\title{
A new "breath" from the European Respiratory Society School
}

We are proud to present the first issue of Breathe, a new initiative from the European Respiratory Society (ERS) and the ERS School. The objective of Breathe is to bring educational material of high quality to the members of the ERS, as well as to other interested readers. For the respiratory physician whose work is mainly clinical, for allied health professionals and for respiratory paediatricians working mainly in the clinical field, Breathe will try to help keep you updated on the different fields of respiratory medicine. Breathe will bring review articles of high quality, interesting and intriguing case reports, reviews of recently published scientific articles in the manner of the former European Respiratory Topic, and material for self study and self-evaluation. All of this will be presented quarterly, with an easy and colourful layout with many illustrations, in order to be easily readable and accessible.

Breathe is not intended to be a scientific journal such as the European Respiratory Journal, but rather make the rich educational resources of the ERS available for more members. Breathe will bring you presentations from the ERS School Postgraduate (PG) courses and the recently introduced ERSSchool courses, and it will be able to concentrate upon certain topics. Breathe hopes to become a journal for the many attendees at the Annual Congress who participate for more educational than for scientific reasons.

Through the recent experiences of the ERS School, the need for new initiatives in education within respiratory medicine in Europe has become evident. Throughout the last year, several new projects have been undertaken by the ERS School. In addition to the PG courses at the annual congress, new School courses at other times of the year, at different locations and more in-depth have taken place, and based upon the experiences so far, will continue next year. These new courses, extending over 3-4 days, enable teachers and participants to communicate on an interactive level with hopefully increased benefit for both parties. The first course on Lung Pathology took place in August in Budapest, and several other courses have already been held on Bronchoscopy (in Crete), Advance Paediatric Respiratory Medicine (in Barcelona), Lung cancer (in Lausanne), Clinical Exercise Testing (in Florence), Infant Lung Function Testing (in Nice) and Non-Invasive Ventilation (in Pisa).

This year, the e-learning resource centre of the ERSSChool has been launched on the ERS website. Here presentations from PG courses and symposia at the Congress have already been presented, along with interactive case reports. One aim is to build a library of images from our field of medicine, at the same time being of educational value, and to be a teaching tool for respiratory physicians throughout Europe.

Breathe aims to add another dimension to the ERS School and to disseminate information from all of its other activities to a wider audience.

In the present first issue of Breathe, Emiel Wouters gives a comprehensive review of rehabilitation for patients with chronic obstructive lung disease. He underlines the importance of a multi-disciplinary approach to rehabilitation, underlining physical training, education of the patients, nutrition and optimal medical
K-H. Carlsen ${ }^{1}$

N. Ambrosino ${ }^{2}$

${ }^{1}$ Voksentoppen Children's Asthma and Allergy Center Oslo Norway

\section{${ }^{2}$ Pulmonary Division} Cardio-Thoracic Department Azienda OspedalieraUniversitaria Pisana Pisa

Italy

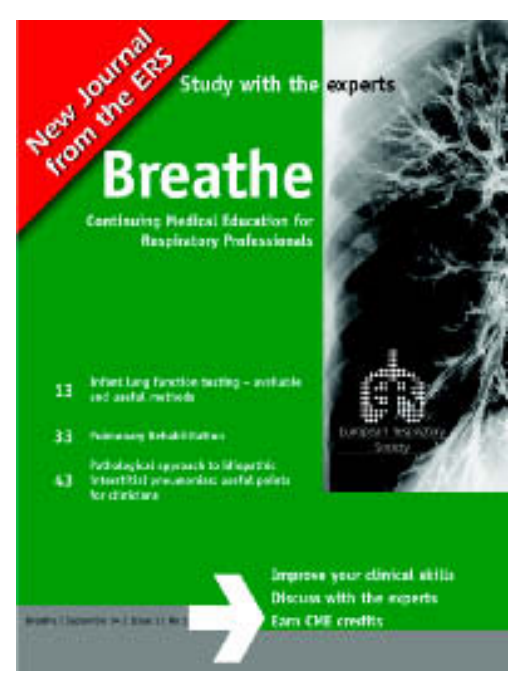




\section{EDITORIAL}

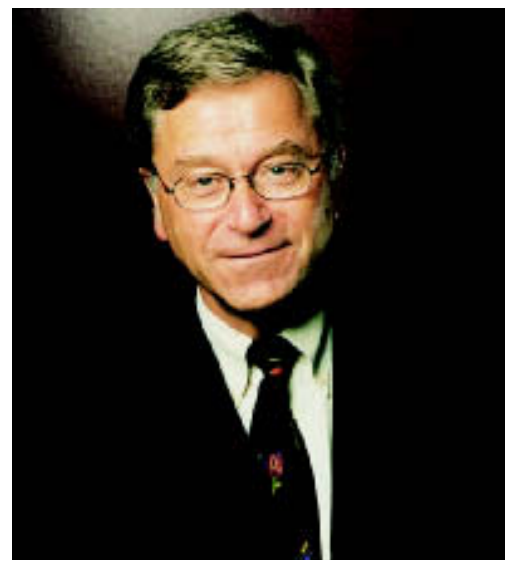

K-H. Carlsen

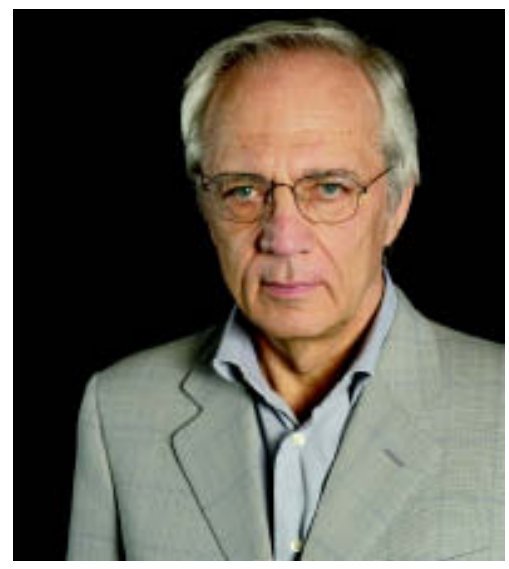

N. Ambrosino treatment, and gives references to guidelines within this topic for those who want to take initiatives within their own community and clinical practice.

Henrik Ljungberg and Per Gustaffson give an introduction and an outline of the different methods of infant lung function testing. They describe these theoretically difficult methods in an instructive and easy to understand way, and give a useful overview of a rapidly developing field.

Ben Nemery is the author of a review article on occupational asthma and Thomas $\mathrm{V}$. Colby gives a review of the pathology of interstitial pneumonias, aimed particularly at the clinician. The latter review article originates from our Lung Pathology course.

In the present first issue of Breathe you will also find some case reports, and reviews of scientific articles, edited by Nicolino Ambrosino.
In the future, in cooperation with different National Respiratory Societies, we hope to be able to bring you Breathe in different major European languages. We hope this approach will make the journal easily accessible for the many clinicians around Europe. We hope that our opinion leaders will accept invitations to write for the journal and, in addition, readers will be welcome to submit their own contributions for assessment for publication within the journal.

We hope you will welcome this new initiative from the ERS School, and that the new journal will be useful and of interest for you in your daily clinical practice.
We would like to invite anyone interested in submitting a Review or Case Presentation to Breathe to read the Instructions to Authors on page 76 or go to www.breathe-cme.org

For more information on ERS School courses and the opportunities available to study with the experts please go to www.ersnet.org/school 